Talía. Revista de estudios teatrales ISSN-e: 2659-806X

http://dx.doi.org/10.5209/TRET.63217

\title{
La censura escénica y literaria del teatro de Luis Vélez de Guevara ${ }^{1}$
}

Javier J. González Martínez*

Recibido: 8 de julio de 2018 / Aceptado: 29 de octubre de 2018

Resumen. El caso de Luis Vélez es significativo en el análisis de la censura por el número de obras afectadas, por la diversidad de censores implicados, por la variedad de temáticas, por los distintos tiempos y por los diferentes procesos identificados (autocensura, solicitud de licencias y prohibiciones). A partir de este dramaturgo se observa que la censura utilizaba los textos como objeto para sustentar un dictamen previo a la representación, pero independientemente de cuál fuese el resultado, no había seguimiento de la transmisión textual. El aparato censor gubernamental del teatro centraba su atención en la exhibición ante las clases populares incultas.

Palabras clave: Teatro, Siglo de Oro, Luis Vélez de Guevara, censura, licencias de representación, lectura, autocensura, literatura

\section{The scenic and literary censorship of the theater of Luis Vélez de Guevara}

Abstract. The case of Luis Vélez is significant in the analysis of censorship due to the number of works affected, the diversity of censors involved, the variety of topics, the different times and the different processes identified (self-censorship, application for licenses and prohibitions). From this playwright it is observed that the censorship used the texts as an object to support an dictum prior to the representation, but regardless of what the result was, there was no follow-up of the textual transmission. The government censor apparatus of the theater focused its attention on the exhibition before the uncultivated popular classes.

Keywords: Theater, Spanish Golden Age, Luis Vélez de Guevara, Censorship, staging licenses, reading, self-censorship, literature

Cómo citar: González Martínez, J.J. (2019). La censura escénica y literaria del teatro de Luis Vélez de Guevara, en Talía. Revista de estudios teatrales, 1, 67-86

La relación del teatro de Luis Vélez con la censura abarca un campo bastante extenso, tanto en número de obras, como en censores implicados, en épocas y en temáticas de la censura. Son quince las piezas del ecijano que pueden servir para estudiar cómo afectaron los distintos procedimientos censores en su creación dramática. Todas ellas presentan uno o varios de estos hechos: tienen notas de aprobación o censura en manuscritos teatrales; contienen en los preliminares del impreso referencias expresas o alusivas a circunstancias relacionadas con la revisión de los textos (aprobaciones, censuras, prólogos del autor, etc.); fueron prohibidas para su publicación o repre-

\footnotetext{
1 Este trabajo es fruto del proyecto de investigación "CLEMIT-Base de datos integrada del teatro clásico español" (financiado por el Ministerio de Economía y Competitividad/FEDER, UE, FFI2015-65197-C3-3-P).

* Universidad Internacional de La Rioja.
} 
sentación; o tienen rasgos que podrían hacernos pensar que sufrieron la censura del propio dramaturgo o del autor de comedias.

Las obras de Luis Vélez que cumplen uno o varios de estos criterios son: La cristianísima lis, y azote de la herejía; El rey en su imaginación; La luna africana; El alba y el sol; La conquista de Orán; La mayor desgracia de Carlos Quinto; El triunfo mayor de Ciro; El pleito que tuvo el diablo con el cura de Madrilejos; El Águila del Agua; También tiene el sol menguante; El catalán Serrallonga, y bandos de Barcelona; Los tres portentos de Dios; El negro del Serafín; La Serrana de la Vera; La Ninfa del cielo ${ }^{2}$. De estas quince comedias, las cinco primeras pasaron la censura sin ningún inconveniente y de forma rutinaria, mientras que las dos últimas no tenemos certeza de que hayan sufrido censura.

El censor del manuscrito fechado en 1622 de La cristianísima lis, y azote de la herejía no solo no pone pegas sino que da la enhorabuena al escritor pues no hay nada que enmendar "tan cuerdo y advertido lo ha escrito"3. Este censor debía ser bastante afecto a Luis Vélez pues unos años después, al revisar El rey en su imaginación vuelve a alabarle diciendo: "Tiene esta comedia que intitula Luis Vélez, su autor, El rey en su imaginación, muy buenos y entretenidos versos, y ningún inconveniente su representación. Puede hacerse" ". La tercera de estas comedias aprobadas sin poner ninguna pega es La luna africana, escrita en colaboración entre nueve ingenios: Belmonte, Luis y Juan Vélez de Guevara, Alfaro, Moreto, Martínez de Meneses, Sigler de Huerta, Cáncer y Rosete. Vemos en esta censura un ejemplo de aprobación rutinaria: "Vista y aprobada muchas veces. Madrid a 16 de enero de 1680. Don Francisco de Avellaneda". El alba y el sol es una pieza dramática dedicada a ensalzar la figura del duque de Lerma. Es un claro ejemplo de obra teatral que no plantea ningún problema al poder establecido, pues la alabanza al valido da beneficios durante el tiempo de bonanza y no es penada cuando el poderoso cae en desgracia. Se conocen anotaciones censoras de este título en dos ocasiones: en un manuscrito del siglo XVIII y en un apunte escénico del siglo XIX. La conquista de Orán pasa también la censura $\sin$ inconvenientes en 1867. Entre las comedias de las que no tenemos testimonio de haber pasado un proceso censor institucional y desconocemos si las tachaduras que presentan son fruto de un proceso creador, censor o de adaptación a la escena se encuentran La Serrana de la Vera y La Ninfa del cielo.

Las personas involucradas en la revisión de estas piezas de Luis Vélez a lo largo del tiempo son José Cañizares, fiscal de comedias (El alba y el sol, Biblioteca Nacional de España -BNE-, manuscrito 16.060); Manuel Luna, Francisco Ramiro y Arcayos, Pablo Muñoz de la Vega, los tres eran censores inquisitoriales, y Manuel Fernando Ruiz del Burgo y Ruiz-Ramírez, censor civil (El alba y el sol, Biblioteca Histórica Municipal -BHM-, Tea 1-5-4, b); Pedro de Vargas Machuca, censor de comedias, y D. de Mello (La cristianísima lis, Biblioteca del Institut del Teatre de Barcelona -BITB-, Vitr. A, Est. 5; y El rey en su imaginación, BNE, Vitrina 7, $\mathrm{n}^{\circ}$ 9); Francisco de Avellaneda (La luna africana, BNE, manuscrito 15.540); Nicolás González Martínez, censor (El triunfo mayor de Ciro, BHM, TEA 1-150-11-A); Juan Navarro de Espinosa, censor (El Águila del Agua, BNE, manuscrito, Res. 111;

2 Ver la ficha de estas piezas dramáticas en la base de datos del proyecto Clemit ("Censuras y licencias en manuscritos e impresos teatrales"), disponible en acceso libre en internet (http://buscador.clemit.es ).

Censura de Pedro de Vargas Machuca en el manuscrito La cristianísima lis, BITB, Vitr. A, Est. 5.

Censura de Pedro de Vargas Machuca en el manuscrito autógrafo El rey en su imaginación, BNE, Vitrina 7, nº 9.

La luna africana, BNE, manuscrito 15.540, f. 68v. 
El negro del Serafin, BNE, manuscrito 17.317; También tiene el Sol menguante, y no hay privanza sin envidia, BNE, manuscrito 15.568); Antonio Nanclares, censor (También tiene el Sol menguante, y no hay privanza sin envidia, BNE, manuscrito 15.568); Gabriel de la Calle, Sancho Dorisa, Diego Sarmiento, estos tres últimos eran inquisidores, Francisco de Tapia, Bartolomé Díaz, Juan de Villamar y Matías de Sobremonte, los cuatro eran calificadores inquisitoriales (Los tres portentos de Dios, Archivo Histórico Nacional -AHN-, suelta adjunta al expediente Inquisición, legajo 4489/3); dos censores desconocidos (El pleito que tuvo el diablo con el cura de Madrilejos, AHN, manuscrito adjunto al expediente Inquisición, legajo 4514); Narciso Serra (La conquista de Orán, AHN, legajo 11.403).

Este corpus de obras dramáticas se estudiará a partir de diversos procesos de censura. Distinguiremos la autocensura, tanto por parte del poeta como por parte del autor de comedias (La Serrana de la Vera, La Ninfa del cielo, El catalán Serrallonga), el proceso de obtención de licencias de representación (La conquista de Orán, El alba y el sol, El Águila del Agua, También tiene el sol menguante, La cristianísima lis, El rey en su imaginación, El triunfo mayor de Ciro, El catalán Serrallonga, La luna africana, El negro del serafin), la solicitud de prohibición (El pleito que tuvo el diablo con el cura de Madrilejos, Los tres portentos de Dios, El catalán Serrallonga, El negro del serafín), la aprobación de representación bajo condiciones ( $L a$ mayor desgracia de Carlos Quinto, También tiene el sol menguante), la prohibición de representación (El pleito que tuvo el diablo con el cura de Madrilejos, El catalán Serrallonga, Los tres portentos de Dios) y la prohibición del impreso (El pleito que tuvo el diablo con el cura de Madrilejos).

Autocensura no es todo lo que tacha un escritor de su propia obra, sino lo que elimina por cuestiones relacionadas con asuntos extraliterarios y extraescénicos. Son consideradas también autocensura las decisiones del autor de comedias que no estén justificadas por criterios de índole escénica. En ocasiones será difícil distinguir la creación del poeta y la intervención del autor. El rastreo de las huellas autocensoras lo hacemos a través de los textos. Las manos del dramaturgo y del autor de comedias se confunden en la conformación de la poesía dramática. Los escritores entregaban las obras a los empresarios teatrales y estos las adaptaban a sus condicionantes. En muchas ocasiones, los textos que llegaban a la censura tenían parte de creación del poeta y parte de creación del autor.

El manuscrito de La Serrana de la Vera que se conserva en la BNE (manuscrito, Res. 101) muestra anotaciones marginales y tachaduras que "forman parte de un proceso creador" del propio Luis Vélez [Bolaños 2001: 75]. Aunque algunos de los atajos y tachaduras también pudieron haber sido hechos por el autor de comedias que se hizo con el texto para su representación. Luis Vélez y el autor utilizarían estos papeles como borrador a medida que pulían la obra. Fue escrita por encargo, expresamente realizada para una compañía y más específicamente para la actriz Jusepa Vaca, por lo que estaría justificado este trabajo colectivo. El manuscrito debió de pertenecer a la compañía de Juan de Morales [Peale 2002: 56], quien muy probablemente manipulase el texto dramático original para convertirlo en un auténtico texto teatral. Estos atajos, indicados por corchetes o rayas, suman 418 versos (un 12,6\% de los 3.305 del total de la obra). Se pueden consultar en detalle en la correspondiente ficha de la Base de datos CLEMIT: allí se verá que han podido ser atajados por moderar la violencia, para abreviar, por decoro, por motivos escénicos, religiosos o políticos. 
El primer atajo es el de una redondilla que, puesta en boca de Jusepa Vaca, podría resultar equívoca, dada la mala fama de la actriz [Bolaños 2001: 54]:

Vuelvo las ancas, aflojo

el freno, doile al ijar

la espuela, y vuélveme a dar

asalto, en su sangre y rojo. (vv. 309-312)

Los vv. 627-630, 632-646 y 871-890 pudieron ser atajados para eliminar equívocos de homosexualidad en referencias a la reina:

GILA. Como los reyes honrar

esta ciudad han querido, toda la Vera ha venido, que no ha faltado lugar. Rabiando vengo por ver a la reina, porque de ella, después de decir que es bella, dicen que es brava mujer, que al lado de su marido, que le guarde Dios mil años, le ven $\mathrm{h}[\mathrm{ac}] \mathrm{er}$ hechos extraños; mas tal madre la ha parido y tal padre la engendró.

MADALENA. Su valor pintado han en el príncipe don Juan.

GILA. Madalena, en viendo yo mujeres de esta manera, me vuelvo de gusto loca. (vv. 627-646)

GILA. Que de vos, alta señora, a muchos días que estoy enamorada, y os doy los parabienes agora de los triunfos que gozáis de las cosas que havéis hecho, que bien el valor del pecho en el semblante mostráis. Ruego a Dios que no paréis hasta ganar a Granada, porque dempués coronada de sus granates quedéis, que dirán bien en la frente de tan divina amazona. Vos tenéis gentil persona y malhaya yo si miente en cuanto dize de vos la fama, y que, si hombre fuera, 
por vos sola me perdiera, y aún así lo estoy, ¡por Dios! (vv. 871-890)

El atajo de los vv. 1131-1174 suprime dos imprudentes ejemplos que pone el gracioso para manifestar a Gila su amor:

Dígalo fray Juan Guarín

y otros muchos que ha[n] tentado

la soledad y han gozado

de altas empresas el fin;

que en cuantas mujeres ves

que casi imposibles son,

alcanza más la ocasión

que el amor ni el interés.

¿Aquel cuento no has oído

de aquel rey que por ahí

dicen que estaba de sí

tan loco y desvanecido, que no pensaba que había otro hombre criado el cielo más perfeto sobre el suelo, y estando mirando un día por los resquicios acaso de una puerta, descubrió a la reina dentro, y vio que tenía, ¡extraño caso!, en los brazos un enano ¡escarmiento de señores! haciéndole mil amores sólo porque le halló a mano, olvidando la hermosura, la grandeza y perfección del rey, porque la ocasión goza de la coyuntura? Ésta ha sido la que a mí, Gila, me da atrevimiento de decirte lo que siento. Ama y volverás por ti, que viéndote tan hermossa, tan moza, tan alentada, tan bien vestida y calzada, tan discreta, tan airosa, los que de las quejas suyas ven que no tienes cuidado, han dicho que lo has dejado por faltas secretas tuyas; $\mathrm{y}$ bien se ve que han mentido, porque no pueden caber 
en tan hermosa mujer

otras faltas que su olvido. (vv. 1131-1174)

Y la censura del cortejo de Mingo parece debida al exceso, tanto por su extensión como por su intensidad:

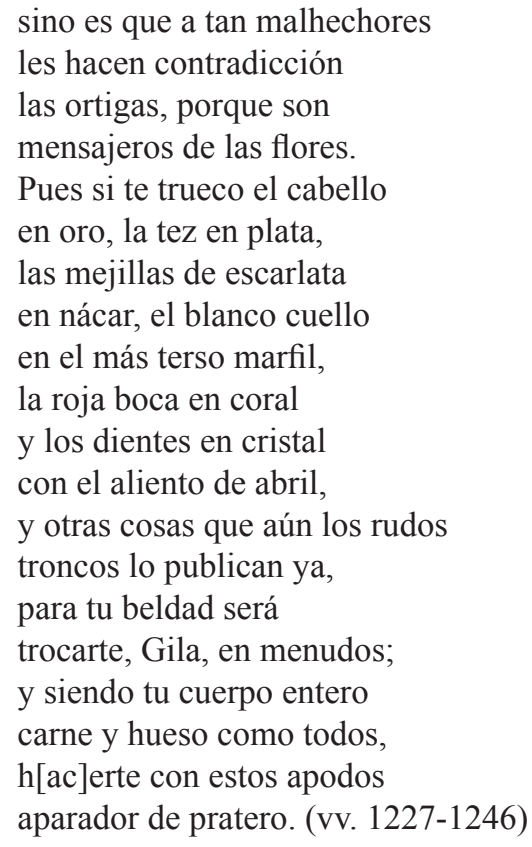

Otro recorte significativo es el de los vv. 2846-2853, que puede justificarse por un deseo de frenar la violencia de la serrana, quien al principio mataba a los que pasaban por allí y ahora parece decidida a ir en busca de sus víctimas:

de poco provecho aquí

si nuevos lances espero.

Entrarme en mi choza quiero

y esperar al sol allí

para volver a buscar

vidas, Gila, en que te cebes.

¡Ah noche!, lo que me debes,

¿cuándo me lo has de pagar? (vv. 2846-2853)

En el recorte del parlamento de Capitán parece subyacer el deseo del dramaturgo por hacer repulsivo a este personaje, a lo que no ayudarían estos bellos versos:

Todo con la sombra vana

me altera y me desconfía;

hidalga cosa es el día cuanto es la noche villana.

¡Oh sol!, de la espuma cana 
saca tu roja cabeza,

restituye la belleza

que robó la sombra oscura,

por que venza tu hermosura

a su cobarde tristeza. (vv. 2884-2893)

Este afán por abreviar la pieza se aprecia sobre todo en los vv. 3128-3179, que dramatizan la delicada situación de poner en boca de reyes palabras sobre temas tan dispares como el amor, los celos y la Inquisición:

FERNANDO. No se puede pintar la gallardía,

la belleza, el valor de la serrana.

ISABEL. Celos me dais, por vuestra vida y mía.

FERNANDO. ¿A vos os puede dar mujer humana

celos, siendo vos cielo de mis ojos?

ISABEL. Tal vez suele agradar una villana

como tosco manjar, que por antojos

da el harto del faisán al apetito.

FERNANDO. Nunca al amor da el gusto esos enojos;

mas necio vengo a ser, pues solicito

daros satisfacción, Isabel mía,

del que vos conocéis, y es infinito.

Dadme esos brazos por que envidie el día

los que yo os diere a vos, si la serrana

a celos con mi amor os desafía;

que por la vida de Isabel y Juana,

que voy con intención de que se prenda,

porque demás de ser tan inhumana,

no hay en la Vera de Plasencia senda

ni camino que de ella esté seguro.

ISABEL. Pues la Hermandad es bien que en eso entienda.

FERNANDO. Sírvenle de defensa y alto muro

esa sierra en que está, y así es en vano

el llegarla a prender; mas yo procuro

con cuatro compañías desde el llano

batirle esos peñascos.

ISABEL. ¿Qué hay, maestre?

RODRIGO. La Hermandad de Plasencia, que con mano

armada asalta esa muralla alpestre

de esos riscos, ha preso a la serrana,

por que el valor de la Hermandad se muestre,

llevándola a Plasencia esta mañana,

adonde habrán de hacer justicia de ella,

sino es que apela a la piedad cristiana

de vuestros pechos.

FERNANDO. La común querella,

los atroces delitos no permi[ten]

que se tenga piedad, Girón, con ella, 
y no es razón que a la Hermandad le quiten, pues que tan nueva está, las exenciones que nuestros previlegios les admiten.

Castiguen como es justo a los ladrones, sin que haya apelación, que de esta suerte se evitarán muy grandes ocasiones, fuera de que ésta ha dado a muchos muerte y la merece por razón de estado.

RODRIGO. Con intención justísima lo advierte vuestra alteza, señor.

ISABEL. Pena me ha dado, sabiendo que es mujer.

NUÑO. Ya las literas

aguardan y las guardas han llegado.

FERNANDO. Partamos a Plasencia. Las primeras

sospechas brevemente os desengañan.

ISABEL. No las tuve jamás por verdaderas, aunque al amor los celos acompañan. (vv. 3128-3179)

Los atajos de los vv. 615-620, 627-630, 632-646, 1131-1174 y 2884-2893, son probablemente del propio Luis Vélez pues "se asemejan a las indicaciones del poeta en la tercera jornada de El catalán Serrallonga y en el tercer acto de El conde don Pero Vélez" [Peale 2002: 56]. Estos recortes van encaminados a resaltar la teatralidad del espectáculo: reducción en el tiempo, simplificación del montaje, adecuación del número de personajes a las posibilidades de la compañía, eliminación de pasajes narrativos y descriptivos y por razones de decoro.

Pero estos atajos producen daños secundarios, pues el texto espectacular que surge tras los atajos no conserva los rasgos trágicos originales del texto literario: "Lo que era una tragedia... se redujo a un melodrama" [Peale 2002: 58]. Tras los recortes realizados cabe distinguir claramente entre un texto literario y un texto espectacular de La Serrana de la Vera, aunque no se puede saber con seguridad si estos versos atajados fueron suprimidos en las representaciones: "Dichos pasajes estaban solamente atajados y no tachados, Morales y compañía podían variar el sentido decoroso de la obra según el público y las circunstancias específicas en el local de representación" [Peale 2002: 60). Como muchas otras obras de Luis Vélez, muy despreocupado por la edición de sus obras, La Serrana de la Vera no fue llevada a imprenta hasta el siglo XX.

Otro ejemplo en el que se puede analizar si hubo autocensura es el del manuscrito de La Ninfa del cielo que se encuentra en la BNE (manuscrito 16.698). No tenemos constancia de que fuese el testimonio remitido para la obtención de licencia, así que las marcas que allí se encuentran es posible que sean del autor de la compañía, en unos casos para adaptar la obra a la escena y en otros quizás por autocensura [Rodríguez 2008: 79-80].

Un tercer caso en el que podríamos comprobar el fenómeno de la autocensura se da en El catalán Serrallonga, y bandos de Barcelona, comedia de Antonio Coello, Francisco de Rojas Zorrilla y Luis Vélez (escribió la tercera jornada), conservada parcialmente en un manuscrito autógrafo (de Rojas y Vélez) fechado en 1634 (BITB, Vitr. A. Est. 5 (5); jornadas segunda y tercera). Pero como las posibles muestras de 
autocensura aparecen en la jornada de Rojas Zorrilla dejamos el estudio de este particular para otro lugar.

Pisamos un terreno más firme al dejar atrás las posibles autocensuras y tratar los procesos de obtención de licencias de representación. Diez de las quince obras del campo de estudio escogido han pasado por esta etapa de censura. Se mencionará algo sobre cada una de ellas según orden cronológico de solicitud de licencia. La cristianísima lis, y azote de la herejía, conservada en un manuscrito de la BITB (Vitr. A, Est. 5) fechado en 1622, contiene la siguiente censura:

Vea esta comedia Pedro de Vargas Machuca.

Esta comedia [que] Luis Vélez de Guevara, su autor, intitula La cristianísima lis es el primer acometimiento que gloriosamente ha hecho a las armas el cristianísimo Luis XIII, rey de Francia. Escribe el caso con toda verdad; de los reyes, con la majestad y decoro que se les debe; y de aquella nación, con la cortesía y alabanza que merece, no dejando el autor cosa en que poderse reparar (tan cuerdo y advertido lo ha escrito).

En Madrid, 20 de noviembre de 1622.

Pedro de Vargas Machuca. [rúbrica]

A pesar de esta laudatoria censura se encuentran en el manuscrito algunos fragmentos tachados o enjaulados o con notas al margen, que no parecen indicaciones escénicas. Sánchez Jiménez concluye que pueden estar dirigidos a elevar el tono serio de la comedia, cuestionando especialmente las intervenciones del gracioso sobre política y religión. Además, en el f. $34 \mathrm{v}$, desconocemos el motivo por el que unas palabras de la reina a Isabela en las que se queja de la ausencia del rey, vienen acompañadas al margen por la nota "Todo esto se ha de borrar".

Este manuscrito presenta unos folios intercalados (ff. 59-61) posiblemente añadidos para dignificar la muerte del personaje del duque de Umena (Sánchez Jiménez). Al final de esta extensión, en el f. 61v, se encuentran las palabras "Podesse representar", tres palabras ilegibles y la firma de D. de Mello. En opinión de Monahan [1991: 139] esta segunda censura puede ser para una representación portuguesa.

El rey en su imaginación, conservada en un manuscrito autógrafo datado en 1625 [BNE, Vitrina 7, $\mathrm{n}^{\circ}$ 9], lleva también licencia de representación firmada por el mismo censor:

Vea esta comedia Pedro de Vargas Machuca.

Tiene esta comedia que intitula Luis Vélez, su autor, El rey en su imaginación, muy buenos y entretenidos versos, y ningún inconveniente su representación. Puede hacerse.

Madrid, 20 de agosto 1625.

Pedro de Vargas Machuca. [rúbrica]

El caso de El catalán Serrallonga, y bandos de Barcelona es extraño en cuanto a su proceso de obtención de licencias. Ya se ha descrito antes el testimonio que conservamos. Lleva una nota, fechada el 8 de enero de 1635, pidiendo que se remita al 
censor Jerónimo de Villanueva, sin embargo, no aparece a continuación la licencia de representación. Sabemos que se llevó a las tablas en espacios públicos y privados. En la suelta de la BHM Tea 1-97-6b se encuentran censura y licencia de representación fechada en mayo de $1776^{6}$. Más adelante volveremos a esta comedia pues tuvo problemas en los siglos XVIII y XIX y llegó a ser prohibida.

El Águila del Agua, comedia cuyo autógrafo se conserva en la BNE (manuscrito, Res. 111), presenta licencia de representación de Juan Navarro de Espinosa, firmada en Madrid en 1642. No se imprimió en su época, ni en siglos posteriores, hasta época moderna. Hay una edición reciente a cargo de C. George Peale, a partir de la cual citamos. En la hoja final del autógrafo aparece esta censura:

He visto esta comedia y, reformando los juramentos de don Lope de Figueroa que tiene en ella, se puede representar.

En Madrid, a 29 de Julio de 1642.

Juan Navarro de Espinosa.

El autógrafo contiene numerosas tachaduras, enmiendas y añadiduras que no pertenecen sólo a la mano del dramaturgo. Las propias del poeta corresponden a la revisión del texto, sobre todo los versos finales de la segunda jornada. También las hay de los responsables de su representación para la adaptación escénica de la pieza: por ejemplo, la eliminación del personaje de Hipólita de la jornada III podría deberse a una condición de la compañía. Algunas modificaciones pueden tener otra interpretación:

La reorientación del Acto III y los cambios como los que acabamos de citar produjeron acusadas notas patrióticas que, si de hecho se realizaron en 1642, debían de tener una particular resonancia ante el trasfondo de los eventos en Cataluña y el traslado de la corte a Zaragoza. [El rey Felipe inició el traslado a Zaragoza dos días antes de la censura firmada por Navarro de Espinosa, es decir, el 27-VII-42] (Peale, Águila 18).

Juan Navarro de Espinosa era uno de los censores de comedias que con mayor atención examinaba cada una de las piezas [Ruano 1989: 228]. Con El Águila del Agua se enfrentará a una obra de tosco realismo que tiene su principal exponente en los juramentos puestos en boca de don Lope de Figueroa7. Valga como muestra el siguiente ejemplo, que responde a uno de los juramentos más repetidos:

\author{
No me ataja \\ ni acobarda, [tachado: ¡voto a Dios!], \\ sino es el Rey, otra humana \\ cosa en el mundo. (vv. 690-694)
}

\footnotetext{
6 Cerezo [2007: 113] y García [2015: 152] tienen razón al localizar el manuscrito Tea 1-97-6a, pero la censura a la que se refieren está en la suelta Tea 1-97-6b. La suelta fue impresa en Madrid, por Antonio Sanz, s.a.

$7 \quad$ El dictamen del censor se aplica nada menos que a veinticinco juramentos suyos y de otros personajes: vv. 43940, 631, 691, 705, 723, 730, 749, 779, 956, 1025, 1069, 1081, 1091, 1169, 1285, 1445, 1462, 1478, 1797, 1996, 2068, 2382, 2850, 2853 (Peale, Águila 16).
} 
El censor se fija especialmente en el personaje don Lope de Figueroa, sin comprender que "los juramentos de don Lope eran parte integrante de su personalidad teatral" [Ruano 1989: 215].

Las particularidades de El negro del Serafín han sido analizadas en González (Transmisión) a partir del manuscrito 17.317 de la BNE. Tiene aprobación censora firmada por Juan Navarro de Espinosa el 8 de febrero de 1643 y licencias de representación de cinco días después. El manuscrito tiene anotaciones muy curiosas, por inusuales en el quisquilloso censor. Reproduzco modernizando la grafía lo que se dice al final de la comedia:

He visto esta comedia y reparando en ella lo que tengo apuntado en el margen de esta tercera jornada en la hoja quince, no siendo inconveniente el ser toda episodio de la vida de este santo, si bien en lo principal, que es lo importante, conviene con su historia, como consta de la crónica del seráfico san Francisco en la cuarta parte. Guardando las demás advertencias que tengo dichas y apuntadas en ella se podrá representar, y no de otra manera, en Madrid a 8 de febrero de 1643. Juan Navarro de Espinosa.

Represéntese, Madrid, 13 de febrero de 1643.

Para Ruano de la Haza, esta censura del severo Navarro de Espinosa evidencia que "incluso las comedias hagiográficas debían conformar con un cierto canon de decencia en estos años" [225]. La hoja de la parte censurada ha sido arrancada, sólo ha quedado una pequeña barba en cuyo vuelto todavía se lee el final de algunas líneas ${ }^{8}$.

En el manuscrito se pueden contar hasta tres caligrafías distintas: la del primer copista, la del censor y la del copista-reformador ${ }^{9}$. El recto del f. 17 comienza con unos versos tachados que están repetidos a la derecha iguales, pero sin tachar. Este es sin duda el cambio más significativo como consecuencia de la censura. Se trata de la sustitución de unos sesenta versos del original ideal del autor primitivo $(\Omega)$ por tantos otros en el manuscrito ${ }^{10}$. En la primera jornada del manuscrito, en f. $8 \mathrm{r}$ se encuentra un curioso comentario escrito al margen por Navarro de Espinosa:

mirad que decis unas

beces Dios, y otras ala

no es como censor esta

advertencia

Un caso parecido de esta confianza del censor Juan Navarro con Luis Vélez lo vemos en el f. 55r de El Águila del Agua, en el manuscrito Res. 111 de la BNE. En este testimonio de censura fechada en 1642, de especial valor porque se trata de un

8 Hoy sabemos (González, Autoría) que en ese folio desaparecido intervenían unos arcángeles. En un próximo artículo sobre la influencia de la censura en la caracterización de los personajes dramáticos se tratará la eliminación de los arcángeles en esta comedia.

9 Sobre las distintas posibilidades de correcciones y atajos hechos por diversas manos trata Urzáiz [2010: 288].

10 En González [2012] se desarrolla cómo afectaron estas indicaciones de Navarro de Espinosa en la transmisión impresa de la comedia. 
autógrafo del dramaturgo, aparece una nota del censor escrita al margen que dice: "repárese el ser capitán el gracioso que hace de galeote". La revisión que hace el censor se caracteriza por la meticulosidad, pero se observa también un cierto interés literario: da indicaciones sobre la rima, sobre la estructura y sobre el estilo.

La siguiente comedia según el orden cronológico de solicitud de licencia de representación es la colaborada También tiene el sol menguante, conservada en la BNE en el manuscrito 15.568 con interesantes notas censoras:

Vea esta comedia el [¿doctor?] Antonio de Nanclares y dé su parecer.

He visto, señor, esta comedia. Y, aunque es verdad que se ha hecho tantas veces, y con aplausos grandes, y que la historia de Castilla y anales de Aragón concuerdan en que don Bernardo de Cabrera murió degollado, [por] respeto de los descendientes me parece mejor no se hable en esto (como va enmendado) y que no se diga todo lo que va borrado y rubricado. Y con esto, queda con toda seguridad esta comedia ajustada y decente; y se puede representar, a mi parecer, salvo mejor. Madrid, 17 de noviembre de 1655 años.

Don Antonio de Nanclares. [rúbrica]

Vea el fiscal Juan Navarro esta comedia y diga su parecer. [rúbrica]

Cumplió la autora en esta comedia con la orden y mandato de V.Sa.

Madrid y noviembre a 19 de 1655.

Fiscal Juan Navarro de Espinosa.

Con las advertencias que en papel aparte hace el fiscal, esta comedia como está hoy, 20 de noviembre 1655, no doy licencia para que se represente. [rúbrica] (ff. 62v-63r)

El personaje histórico del siglo XIV al que se refiere la censura, Bernardo de Cabrera, fue gobernador del reino y almirante de la escuadra, decapitado por orden de Pedro IV de Aragón a causa de su oposición a Enrique de Trastámara y su deseo de negociar la paz entre su rey y Pedro I de Castilla. Posteriormente su memoria fue restituida y sus herederos gozaron de nuevo del reconocimiento real. Como sostiene Mackenzie [1993: 142]:

Para cumplir los deseos del fiscal ciertos pasajes fueron tachados y otros insertados a fin de evitar la degollación de don Bernardo. En la versión modificada este sigue viviendo y el drama adquiere un nuevo desenlace feliz, no sólo nada histórico sino totalmente diferente de la conclusión creada y deseada por sus coautores.

En la primera jornada se encuentran varios enjaulados con noes y rúbricas del censor, tanto largos pasajes (ff. 15r-16r) como palabras sueltas. La segunda jornada no tiene, aparentemente, ninguna intervención de la censura. En la tercera se localizan los pasajes censurados más largos y relevantes. Es el único caso de este grupo de obras de Luis Vélez que no obtiene licencia de representación en el momento de solicitarlo, 1655, aunque nos constan puestas en escena posteriores ${ }^{11}$. Al ser una

11 Ferrer en el Diccionario biográfico de actores del teatro clásico español (DICAT) documenta representaciones de esta comedia el 11 y 17 de diciembre de 1673, en el Corral de la Cruz, por la compañía de Manuel Vallejo. Y Urzáiz [2002: vol. II, 706] referencia una representación en 1685. 
comedia de colaboración se pospone su análisis detallado a un estudio específico de la censura en este grupo de obras.

La luna africana, otra comedia escrita en colaboración, en esta ocasión con la magnífica participación de nueve manos, se puede consultar en la BNE (manuscrito 15.540), con la siguiente anodina y formulista nota de la censura:

El censor y el fiscal vean esta comedia intitulada La luna africana, y con lo que dijeren, se traiga.

Madrid y enero a 15 de 1680. [rúbrica]

Vista y aprobada muchas veces.

Madrid a 16 de enero de 1680.

Don Francisco de Avellaneda. [rúbrica] (f. 68v)

El alba y el sol es la primera licencia de representación de obra de Luis Vélez que conservamos del siglo XVIII. Se puede consultar en la BNE (manuscrito 16.060):

Madrid 17 de octubre. Lean censor y fiscal esta comedia y con lo que dijeren traspase. [rúbrica]

Esta comedia de El alba y el sol, tantas veces repetida, no tiene cosa que se oponga a nuestra política y bonas mores, y se manda dar lo que fuere servido.

Madrid octubre 21 del 1728. [rúbrica]

Don José de Cañizares.

Madrid 24 de octubre de 1728.

Hágase. [rúbrica]

También se conocen licencias de representación de esta pieza en el siglo XIX (1815-1816), a cargo de vicarios eclesiásticos y miembros de la Suprema y General Inquisición, que no encontraron sino "defectos poéticos en algunos de sus versos", pero "nada contra la sana moral". Mucho más duro es el crítico teatral del periódico El Censor (tomo 14, edición de 1822), que sostiene que El alba y el sol "atormenta el buen gusto de los espectadores, ofende al decoro y a la dignidad nacional" [ctd en Peale, 2010: 59).

Otra de las comedias con censura del siglo XVIII es El triunfo mayor de Ciro, que se conserva en un apunte teatral de 1767 en la BHM (TEA 1-150-11-A). Se trata de un apunte segundo ${ }^{12}$ y presenta indicaciones de movimiento, de entrada y salida de actores, de música, etc. El manuscrito muestra las siguientes notas de la censura:

Nos, el Dr. don Manuel ... Torres, presbítero, abogado de los Reales Consejos, dignidad de Arcipreste de la Insigne Colegiata de la Villa de Talavera y vicario de esta de Madrid y su partido ... por la presente, y por lo que a nos toca, damos licencia para que se pueda representar la comedia intitulada El triunfo mayor de Ciro, saber vencerse a sí mismo; mediante que de nuestra orden ha sido reconocida y no contiene cosa que se oponga a nuestra santa fe católica y buenas costumbres.

\footnotetext{
12 Para las particularidades de los apuntes teatrales y su contexto en relación a la censura puede consultarse González [2014].
} 
Dada en Madrid, a diez de octubre de mil ... sesenta y siete. [firma] (f. 19v, tercera jornada; Papel añadido al tercer cuadernillo; al final del folio se escribe en otra letra: "Por su mano", después unas palabras ininteligibles y a continuación "Dagzo" (Daganzo). Al final del folio, y de una tercera mano, se lee: "Representar").

Madrid, 13 de octubre de 1767.

Pase esta comedia titulada El triunfo mayor de Ciro al censor para su examen y con lo que dijere tráigase. [firma]

Madrid, 16 de octubre de 1767.

Señor, El triunfo mayor de Ciro, que así se titula esta comedia, omitiéndose unos versos que en la segunda jornada van tachados, no tiene otra cosa que pueda prohibir su representación si fuere del agrado V.S. conceder el permiso. Así lo siento, salvo etcétera.

Nicolás González [Martínez].

Madrid, 17 de octubre de 1767. Ejecútese. [firma]

Ejecútese guardando la prevención antecedente.

Madrid y octubre 28 de 1767. Barcia. (f. 21r)

En el manuscrito encontramos huellas del censor que revisó la obra, quien otorgó la licencia de representación pero con orden de omitir los siguientes versos:

ALGODÓN. [tachado: Pues yo, ganas de comer

tengo siempre; de tal modo,

que apetito no le ha habido

menester; y así, he comido,

sin apetito, de todo]. (vv. 970-974)

El censor marca estas líneas con una llave al margen y escribe: "Omítase esto por lo claro" [rúbrica]. Otra letra, distinta de la del censor y de la del copista, propone para la sustitución que Algodón diga: “Con nada te ha de coger?”.

La conquista de Orán es la última de las comedias de Luis Vélez que obtuvo licencias de representación. No sabemos con seguridad que se trate de la pieza de Luis Vélez, pues en el expediente de censura (AHN, legajo 11.403, no 408) que nos ha llegado solo figura el título y se hace constar que tiene tres actos y está escrita en verso. Desde el Gobierno de la provincia de Valencia se dirigen al Ministro de la Gobernación en los siguientes términos:

Excmo. señor. Aceptado por la empresa de los teatros de esta capital el drama en tres actos y en verso titulado La conquista de Orán, tengo el honor de elevar a V.E. los dos ejemplares adjuntos que previene la ley para los efectos de la censura. Dios guarde a V.E. muchos años. Valencia 9 de noviembre de 1867.

Poco después el censor aprueba la comedia:

Excmo. señor. Tengo el honor de remitir a V.E. el drama en tres actos y en verso titulado La conquista de Orán, que examinado, no hallo inconveniente en que su 
representación se autorice. Dios que a V.E. guarde muchos años. Madrid 16 de noviembre de 1867. Excmo. Señor. El Censor de Teatros, Narciso Serra.

En cuanto al grupo de obras que fueron prohibidas o al menos se debatió su posible prohibición, tres de ellas (También tiene el sol menguante, La mayor desgracia de Carlos Quinto y El negro del serafín) no fueron finalmente prohibidas o no lo fueron permanentemente. Como ya se ha visto más arriba, la resolución del proceso de También tiene el sol menguante no fue propiamente la prohibición, sino una denegación puntual de licencia de representación pues sabemos que fue escenificada poco después. El caso de La mayor desgracia de Carlos Quinto ha sido tratado en González (Motivos). En resumen, se trata de una obra que representa el desastre sufrido por la flota capitaneada por el mismo Carlos V y el duque de Alba, que consigue finalmente conquistar Túnez. Felipe IV y el príncipe de Gales, futuro Carlos I de Inglaterra, formaban parte del distinguido público que presenció su estreno. Al día siguiente se iba a exhibir en el corral de comedias para el público general, pero no debió de parecer oportuna su representación debido a la presencia de nobles ingleses en la capital. A causa quizás de lo precipitado de la prohibición, ya que se anunció cuando el público esperaba el comienzo de la función, hubo altercados. Esto hizo que al día siguiente, el Consejo de Castilla se retractase y diese permiso para ponerla en cartel. Esa misma tarde el público pudo disfrutar de la obra. En relación a El negro del serafin, consta una denuncia por parte de un particular a la Inquisición, pero esta decide en 1744 que la comedia no tiene nada censurable y sí el delator "que se arroja a decir que no cometió pecado venial el fray Benito, no constando semejante cosa"13.

Las tres comedias que fueron prohibidas son Los tres portentos de Dios, El pleito que tuvo el diablo con el cura de Madrilejos y El catalán Serrallonga. La primera de ellas constituye el único caso de comedia exclusiva de Luis Vélez que fue prohibida. Los tres portentos de Dios fue objeto de un expediente de calificación (Valladolid, noviembre de 1658), caso que publicaron en su día Paz y Melia y Simón Díaz, sobre el que más recientemente ha aportado algún dato adicional Agustín de la Granja y que ha analizado en detalle Urzáiz (Profundidad). Conocemos la censura de la comedia a través de la suelta conservada en AHN (sección Inquisición, legajo 4489). El autor de comedias Francisco de la Calle remitió a la Inquisición la comedia. La Inquisición la encomendó a varios calificadores que encontraron los siguientes motivos de censura: la violencia ejercida por san Pablo sobre el hijo de la viuda de Naín y Lázaro, las pretensiones amorosas del mismo a la Magdalena, ciertas declaraciones de Barrabás, alusiones ofensivas contra personas y contra la religión, discursos teológicamente erróneos, acciones y palabras lascivas [Peale 2011: 60]. Por todo esto se solicitó al Consejo de Castilla que la prohibiera:

En la Inquisición de Valladolid, a 14 de noviembre de 1658, estando en su audiencia de la mañana los señores inquisidores Dr. D. Gabriel de la Calle y el Dr. D. Sancho Dorisa y don Diego Sarmiento, habiendo visto esta comedia intitulada Los tres portentos del cielo, compuesta por Luis Vélez de Guevara, y las calificaciones y censuras sobre ella dadas por los padres calificadores, que están con ella, dijeron

13 AHN, sección Inquisición, legajo 4460, expediente 3. Citado desde Paz y Melia [1947: 85]. Aunque el título que figura es El negro del mejor amo, de Mira de Amescua, se ha demostrado en González [2014] que esta referencia es una copia modificada de la pieza de Luis Vélez. 
que se notifique al autor de la compañía de comediantes, que al presente está en esta ciudad, que es el que la [ha] exhibido en este Santo Oficio para censurarla, que no la represente ni consienta representar a ninguno de su compañía en esta ciudad ni otra parte, pena de cien ducados para gastos desta Inquisición y de excomunión mayor; y que, si tiene otro traslado o traslados, lo exhiba (so las dichas censuras y penas) y los papeles que para representarla tuviere repartidos dentro de un día; $\mathrm{y}$, hecho esto, se remitan estos autos a los señores del Consejo para que, siendo servidos, se mande recoger esta dicha comedia por edictos, con penas y censuras en la forma ordinaria; y lo rubricaron ante mí, don Agustín de Cervatos y Velasco.

En el mismo legajo, margen superior izquierdo, de mano distinta está escrito: "En Madrid a 19 de noviembre de 1658. Su Ilustrísima en el Consejo”. Más abajo, también en una nota marginal a la izquierda, se lee lo siguiente:

En Madrid, 22 de noviembre de 1658. El señor Don Lorenzo traiga al Consejo el traslado desta comedia que está en su poder con las calificaciones que a ella se han dado. [rúbrica]

Según las Ordenanzas de teatro de 1608 y 1615, el Consejo de Castilla, a través del Juez Protector de Comedias, era el responsable de dar o no licencias [Florit 2017: 29-30]. Desconocemos cuál fue el dictamen final pues no nos ha llegado ningún testimonio de representación de esta comedia hasta el momento.

Las siguientes comedias prohibidas son obras de colaboración en las que participa Luis Vélez. El pleito que tuvo el diablo con el cura de Madrilejos es la segunda que se distingue por tener auto inquisitorial dirigido al Consejo. Esta comedia además es la única que tuvo problemas censores relacionados con su impresión y no solo con su representación. Tampoco sería de extrañar si Luis Vélez fuese tan afortunado como lo fue con la publicación de La montañesa de Asturias, que se imprimió en la Parte XXX de la Colección de Comedias Escogidas bajo la aprobación de su propio hijo Juan Vélez de Guevara. Aunque este le dedicó poco entusiasmo pues repite "las mismas palabras" que escribió Fray Juan de Vitoria once años antes en el tomo XXV: "[estas comedias] están llenas de casos raros, que pueden seruir de exemplares al desengaño de los hombres" [citado a partir de Wilson 1965: 169].

El pleito que tuvo el diablo con el cura de Madrilejos, de Luis Vélez de Guevara, Rojas Zorrilla y Mira de Amescua, ha sido estudiada por Sánchez e Ibáñez, Madronal y Granja. Las dos censuras inquisitoriales contra esta comedia son: 1) Censura de la comedia El pleito entre el cura y el demonio (AHN, sección Inquisición, legajo 4514, expediente $\mathrm{n}^{\circ} 13$ ); 2) Censura de la comedia El cura de Madrilejos (AHN, sección Inquisición, legajo 4514, expediente $n^{\circ} 8$ ).

Son numerosos los versos y pasajes atajados por los censores, pero es una desaprobación a la comedia en su totalidad, aunque la tercera jornada sea la que lleva más carga de correcciones. Por las características de nuestro análisis, centrado específicamente en el teatro de Luis Vélez, mencionaremos solo algún ejemplo de la primera jornada, de la que es responsable. Desde la acotación inicial la censura ve motivos de prohibición:

La salida primera al tablado es una procesión encaminada a una ermita a decir una misa del Espíritu Santo con todas las circunstancias de procesión eclesiástica de 
cruces, pendón y cura, etc., y se advierte en la nota que los graciosos vayan vestidos de tales. Hecha la procesión se quedan en el tablado los que llevaban las cruces a tratar de amores con estilo bastante deshonesto, de suerte que la procesión que se forma para una misa es para empezar un entremés deshonesto (citado a partir de Urzáiz, Tapándole 184).

El censor corrige especialmente muchas intervenciones del personaje gracioso, Tembleque, como la siguiente:
De Caín Tembleque vengo:
mira Marina, si basta
para hacerme esposo tuyo
ser de tan gran tronco rama;
y serán, Marina hermosa,
si tú conmigo te casas,
Eva y Adán suegros tuyos,
como quien no dice nada. (vv. 131-138)

El pleito que tuvo el diablo con el cura de Madrilejos fue prohibida en 1771 y entró en el Î́ndice de Rubín de Ceballos en 1790, convirtiéndose en la primera y única pieza dramática de Luis Vélez condenada también para su difusión y lectura.

La última pieza que se atenderá, El catalán Serrallonga, vimos que tenía solicitud de licencia, pero no nos ha llegado su resolución. Sin embargo, sabemos que en México la comedia se pidió prohibir con fecha 23 de julio de 1790:

Debe suprimirse El catalán Serrallonga por estar concebida en el mismo gusto [que otra que pedía prohibir anteriormente] y contener la milagrosa aparición de un muerto, que cuando no sea falsa, es uno de aquellos sucesos que deben ocultarse al vulgo porque no tome vocación de delinquir con esperanza de perdón [García 2015: 123].

Y más adelante, en España, pasó a engrosar las filas de la "Lista de las piezas dramáticas que conforme a la Real Orden de 14 de febrero de 1800 se han recogido, prohibiéndose su representación en los teatros públicos de Madrid y de todo su reino". Los motivos de esta inclusión eran de cariz civil, pues se ponía como modelo a un delincuente, y estético:

Los neoclásicos consideraban que el teatro que se representaba en España no se ajustaba a su programa ideológico. Para poner un poco de orden en lo que ellos concebían como un caos se tomaron diferentes medidas que regulaban desde el nuevo estatuto de los comediantes hasta la administración de los corrales y, por supuesto, la programación. Por ello, se elaboró una lista de comedias que debían desterrarse de los escenarios. Dicha lista, en la que figuraban 616 títulos, se publicó en los preliminares de los seis volúmenes de la colección de Teatro Nuevo Español [Julio 2008: 61].

En los distintos procesos que se han analizado (autocensura, solicitud de licencias de representación y prohibiciones) hemos encontrado motivos políticos (La mayor 
desgracia de Carlos Quinto, El catalán Serrallonga), motivos religiosos (El pleito que tuvo el diablo con el cura de Madrilejos, Los tres portentos de Dios) y el posible daño a la fama de alguien o de sus descendientes (También tiene el sol menguante, El pleito que tuvo el diablo con el cura de Madrilejos).

Se puede concluir que, de las trece comedias de Luis Vélez que pasaron por procesos censores externos, cinco de ellas tuvieron como resolución la denegación puntual de representación o la prohibición permanente, aunque a una de ellas le fue levantado el veto rápidamente (La mayor desgracia de Carlos Quinto). De las cuatro restantes, tres son comedias de colaboración (También tiene el sol menguante, El catalán Serrallonga y El pleito que tuvo el diablo con el cura de Madrilejos) y solo una es exclusiva de Luis Vélez (Los tres portentos de Dios). En el caso del dramaturgo ecijano se observa que sus principales problemas con la censura procedían de obras elaboradas con otros escritores. Como en este estudio se trata la censura en el teatro genuino de Luis Vélez, se aplaza para otro trabajo futuro el curioso caso de la censura en comedias de colaboración.

El pleito que tuvo el diablo con el cura de Madrilejos se prohibió por un edicto en 1771 y fue incluida en el Índice en 1790. Después de estas fechas no se volvió a publicar, hasta la presente edición moderna (Peale, Bolaños y Madroñal), ni nos consta representación alguna.

Los tres portentos de Dios se prohibió representar con fecha 1658. No hay constancia de escenificaciones posteriores. Después de su prohibición para ser llevada a las tablas, sí que fue impresa: en 1732 y entre 1741-1748 [Peale 2011: 63-64].

El catalán Serrallonga se prohibió por Real Orden de 14 de febrero de 1800 en los teatros públicos de Madrid y todo su reino, pero su efecto no fue muy duradero:

ese mismo año, tan sólo tres meses después de la fecha de la Real Orden, se representó en Barcelona y, tras esta fecha, siguió presente en los escenarios tanto de la ciudad condal, como del resto de España [García 2015: 124].

Hasta donde sabemos hoy, se volvió a imprimir por primera vez después de la prohibición en el número LIV de la colección Biblioteca de Autores Españoles en 1861. También tiene el sol menguante no obtuvo la licencia de representación en 1655. El censor señaló que no podía representarse tal y como estaba "[por] respeto de los descendientes". Sin embargo, como se ha señalado más arriba, se representó en 1673 y 1685 . Y se imprimió en 1666 y en otras ocasiones más adelante.

Por lo que se observa en los cuatro casos de obstaculización de la representación, estas no traían consigo la prohibición de impresión (También tiene el sol menguante, Los tres portentos de Dios y El catalán Serrallonga) a no ser que fuese explícitamente también prohibida por la inclusión en el Índice (El pleito que tuvo el diablo con el cura de Madrilejos). En el campo del teatro la censura utilizaba los textos como objeto material para sustentar un análisis previo a la representación. Una vez revisados, independientemente de cuál fuese el resultado, no había seguimiento de la transmisión textual. Lo que realmente importaba era la exhibición escénica y no su lectura. Esto tiene su explicación si tenemos en cuenta los índices de alfabetización de los siglos XVII y XVIII. Sin embargo, la literatura dramática se imprimía y se vendía, por lo que tendría sus lectores. Pero se ve que este público lector supuestamente cultivado no estaba en el foco de atención. "Fueron iniciativas gubernamentales las que impusieron las diversas medidas para controlar el teatro a partir de 1598" 
[Close 2003: 276]. Este aparato censor centraba su atención realmente en el vulgo, en las clases populares incultas, posiblemente porque las consideraba más expuestas a ser manipuladas por la opinión pública, por agentes políticos extranjeros o por teorías heréticas. $\mathrm{Al}$ menos en dos ocasiones hemos leído censuras en las que se decía explícitamente que se corregían porque no convenía que conociera el vulgo lo que allí se representaba (Los tres portentos de Dios y El catalán Serrallonga). Esto daría sentido al origen de la censura teatral como iniciativa gubernamental.

\section{Bibliografía}

Bolaños, Piedad (ed.) (2001): La serrana de la Vera, de Luis Vélez de Guevara, Madrid, Castalia.

Cerezo Rubio, Ubaldo, Rafael González Cañal y Germán Vega García-Luengos (2007): Bibliografía de Francisco de Rojas Zorrilla, Kassel, Reichenberger.

Close, Anthony J. (2003): "Lo cómico y la censura en el Siglo de Oro, II", Bulletin Hispanique, 105-2: 271-301.

Ferrer, Teresa (2008): Diccionario biográfico de actores del teatro clásico español (DICAT), Kassel, Edition Reichenberger, DVD.

Florit, Francisco (2017): "Pensamiento, censura y teatro en la España del Siglo de Oro", Pensamiento y literatura en los inicios de la modernidad, ed. Jaume Garau, Nueva York, IDEA: 21-46.

García, Almudena (2015): "Estudio introductorio", en El catalán Serrallonga, de Antonio Coello, Francisco Rojas Zorrilla y Luis Vélez de Guevara, Madrid/Frankfurt, Iberoamericana/Vervuert: 8-198.

González, Javier J. (2013): "Una autoría a partir de una censura", en El teatro barroco revisitado. Textos, lecturas y otras mutaciones, ed. Emilia Deffis et al., Puebla, El Colegio de Puebla: 409-426.

- (2014): "La autoría del apunte teatral El triunfo mayor de Ciro y la impresa Araspas y Pantea", Revista de Filología Española, 94-1: 107-126.

- (2010): "Los motivos de la censura civil de La mayor desgracia de Carlos Quinto, de Luis Vélez de Guevara", en Cuatrocientos años del "Arte nuevo de hacer comedias" de Lope de Vega. Actas selectas del XIV Congreso de la AITENSO (Olmedo, julio de 2009), ed. Germán Vega García-Luengos y Héctor Urzáiz Tortajada, Valladolid, Olmedo Clásico-Universidad de Valladolid: 563-571.

- (2012): "La transmisión impresa de un manuscrito dramático censurado: el caso de $E l$ santo negro, El negro del Serafin o El negro de mejor amo", Castilla, 3: 403-417.

Granja, Agustín de la (2006): "Comedias del Siglo de Oro censuradas por la Inquisición (Con noticia de un texto mal atribuido a Rojas Zorrilla)", en El Siglo de Oro en escena. Homenaje a Marc Vitse, Toulouse, PUM-Consejería de Educación de la Embajada de España en Francia: 435-448.

Julio, María Teresa (2008): "El catalán Serrallonga y bandos de Barcelona en la cartelera teatral barcelonesa", Teatro de palabras: revista sobre teatro áureo, 2: 57-69.

Mackenzie, Ann L. (1993): La escuela de Calderón. Estudio e investigación, Liverpool, Liverpool University Press.

Madroñal, Abraham (2006): "Un documento inédito relacionado con la comedia El pleito que tuvo el Diablo con el cura de Madrilejos", en Antonio Mira de Amescua. Teatro completo. Vol. VI, ed. Agustín de la Granja, Granada, Universidad de Granada: 663-680. 
Monahan, Caroline (1991): “Luis Vélez de Guevara's La cristianísima lis: A ‘LostPlay’ Rediscovered", en Golden Age Spanish Literature. Studies in Honour of John Varey by his Colleagues and Pupils, eds. Charles Davis y Alan Deyermond, London, Westfield College: 137-144.

Paz y Melia, Antonio (1947): Papeles de Inquisición. Catálogo y extractos, Madrid, Archivo Histórico Nacional, (1907).

Peale, C. George, y William R. Manson. Eds. (2003): El Águila del Agua, de Luis Vélez de Guevara, Newark, Delaware, Juan de la Cuesta.

- y William R. Manson. Eds. (2010): El alba y el sol, de Luis Vélez de Guevara, Newark, Delaware, Juan de la Cuesta.

- Piedad Bolaños y Abraham Madroñal. Eds. (2012): El pleito que tuvo el diablo con el cura de Madrilejos, de Luis Vélez de Guevara, Mira de Amescua y Francisco de Rojas Zorrilla, Newark, Delaware, Juan de la Cuesta.

- y William R. Manson. Eds. (2002): La Serrana de la Vera, de Luis Vélez de Guevara, Newark, Delaware, Juan de la Cuesta.

- y William R. Manson. Eds. (2011): Los tres portentos de Dios, de Luis Vélez de Guevara, Newark, Delaware, Juan de la Cuesta.

Rodríguez López-Vázquez, Alfredo. Ed. (2008): El condenado por desconfiado [atribuido a Tirso de Molina] / La Ninfa del cielo [Luis Vélez], Madrid, Cátedra.

Ruano de la Haza, José María (1989): "Dos censores de comedias de mediados del siglo XVII". Estudios sobre Calderón y el teatro de la Edad de Oro. Homenaje a Kurt y Roswitha Reichenberger, ed. Francisco Mundi Pedret et al, Barcelona, PPU: 201-229.

Sánchez, Francisco José, y Álvaro Ibáñez. Ed. (2006): El pleito que tuvo el Diablo con el cura de Madrilejos, Antonio Mira de Amescua. Teatro completo. Vol. VI, ed. Agustín de la Granja, Granada, Universidad de Granada: 335-432.

Sánchez Jiménez, Raquel. "Luis Vélez de Guevara y la contrarreforma: La cristianísima Lis", eHumanista, en prensa.

Simón Díaz, José (1947): "La Inquisición prohíbe Los tres portentos del cielo de Vélez de Guevara"", en Aportación Documental para la Erudición Española. Documentos para la Historia de la Literatura Española. Primera serie, Suplemento $n^{\circ} 2$ de Revista Bibliográfica y Documental, Madrid, CSIC: 3-4.

Urzáiz, Héctor (2002): Catálogo de autores teatrales del siglo XVII, vol. 2, Madrid, Fundación Universitaria Española.

- (2010): "Estrategias cómicas de Moreto frente a la censura moral del teatro: el caso de Antíoco y Seleuco", en Cuatro triunfos áureos y otros dramaturgos del siglo de oro, eds. Aurelio González, Serafín González, Lillian von der Walde Moheno, México, El Colegio de México-Universidad Autónoma Metropolitana-AITENSO: 273-296.

- (2012): “ 'Sacado de la profundidad de la Sagrada Escriptura': la materia bíblica y la censura teatral áurea", en La Biblia en el teatro español, Vigo, Academia del Hispanismo: 283-304.

- (2013): “Tapándole las vergüenzas a la comedia: censura y teatro clásico", en La desvergüenza en la comedia española, Ciudad Real, Universidad de Castilla-La Mancha: 179215.

Wilson, Edward M. (1965): "Nuevos documentos sobre las controversias teatrales: 16501681”, en Actas del II Congreso de la Asociación Internacional de Hispanistas, eds. Jaime Sánchez Romeralo y Norbert Poulussen, Nijmegen, The Spanish Institute of the University of Nijmegen: 155-170. 